\title{
Leukemic Cluster Growth in Culture Is an Independent Risk Factor for Acute Myeloid Leukemia and Short Survival in Patients with Myelodysplastic Syndrome
}

\author{
Michael Bernimoulin ${ }^{\mathrm{a}} \quad$ Martin Stern $^{\mathrm{a}} \quad$ André Tichelli $^{\mathrm{a}} \quad$ Martine Jotterand $^{\mathrm{b}}$ \\ Alois Gratwohl ${ }^{\mathrm{a}}$ Catherine Nissen ${ }^{\mathrm{a}}$

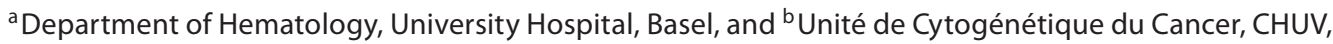 \\ Lausanne, Switzerland
}

\section{Key Words}

Colony-forming unit cells $\cdot$ Leukemic growth .

Myelodysplastic syndrome •

\begin{abstract}
In patients with myelodysplastic syndrome (MDS) precursor cell cultures (colony-forming unit cells, CFU-C) can provide an insight into the growth potential of malignant myeloid cells. In a retrospective single-center study of 73 untreated MDS patients we assessed whether CFU-C growth patterns were of prognostic value in addition to established criteria. Abnormalities were classified as qualitative (i.e. leukemic cluster growth) or quantitative (i.e. strongly reduced/absent growth). Thirty-nine patients (53\%) showed leukemic growth, 26 patients (36\%) had strongly reduced/absent colony growth, and 12 patients showed both. In a univariate analysis the presence of leukemic growth was associated with strongly reduced survival (at 10 years 4 vs. $34 \%, p=$ 0.004 ), and a high incidence of transformation to AML (76 vs. $32 \%, p=0.01)$. Multivariate analysis identified leukemic growth as a strong and independent predictor of early death (relative risk 2.12, $\mathrm{p}=0.03$ ) and transformation to $\mathrm{AML}$ (relative risk 2.63, $\mathrm{p}=0.04$ ). Quantitative abnormalities had no significant impact on the disease course. CFU-C assays have
\end{abstract}

a significant predictive value in addition to established prognostic factors in MDS. Leukemic growth identifies a subpopulation of MDS patients with poor prognosis.

Copyright $\odot 2008$ S. Karger AG, Basel

\section{Introduction}

Myelodysplastic syndromes (MDS) are characterized by maturation defects in one or several hematopoietic cell lineages resulting in peripheral blood (PB) cytopenia [1, 2]. The clinical course varies from chronic mild anemia, thrombocy topenia or leukopenia to rapid leukemic transformation and death. Treatment options range from supportive care (transfusions and hematopoietic growth factors) in patients with symptomatic cytopenia to immunosuppressive therapy with ATG/cyclosporine, if an autoimmune component is suspected, or AML-like chemotherapy for patients with elevated blast cell counts. Cure can be achieved with hematopoietic stem cell transplantation in younger patients [3]. More recently, drugs such as demethylating agents and immunomodulatory

Michael Bernimoulin and Martin Stern contributed equally to this paper.

\section{KARGER}

Fax +4161306 1234 E-Mail karger@karger.ch www.karger.com (c) 2008 S. Karger AG, Basel

0001-5792/08/1194-0226\$24.50/0

Accessible online at:

www.karger.com/aha
Martin Stern, MD

Department of Hematology, University Hospital

Petersgraben 4

$\mathrm{CH}-4031$ Basel (Switzerland)

Tel. +41 6132873 90, Fax +4161265 44 50, E-Mail sternm@uhbs.ch 
drugs have become available; they possibly improve the outlook for MDS patients not eligible for more intensive treatment [4].

The choice of treatment for individual patients depends on diagnostic and prognostic criteria, the age of the patient, and availability of a stem cell donor. The WHO disease classification [5] and the International Prognostic Scoring System (IPSS score) [6] have largely replaced the original French-American-British (FAB) classification of MDS [7, 8]. Favorable prognostic factors include maturation defects restricted to one cell line, low myeloblast count, absence of cytogenetic abnormalities or presence of certain alterations such as isolated deletion of $5 q[9,10]$, and presence of ringed sideroblasts [11]. On the other hand, multilineage dysplasia, a high blast count, cytogenetic abnormalities such as those involving chromosome 7 and presence of a complex karyotype are poor prognostic signs $[12,13]$. The WHO classification and the IPSS score are currently used to assess the prognosis of an individual patient and are the basis for therapeutic decisions $[14,15]$.

Less broadly accepted prognostic factors include bone marrow (BM) hypocellularity as a favorable factor [16] and BM fibrosis as an adverse factor [17, 18]. More recently the prognostic significance of several other parameters, such as LDH value [19] and DNA microarray analysis $[20,21]$, have been investigated. Their independent prognostic value remains to be established. Despite these advances the prediction of outcome and thus the choice of adequate primary treatment often remain unsatisfactory, particularly for patients classified to be at 'intermediate risk', representing the majority of MDS patients $[1,22,23]$.

Soon after the detection of the colony-forming precursor cell, colony-forming unit cell (CFU-C) assays became a useful diagnostic tool in the clinical assessment of patients with AML and MDS. Quantitative and qualitative abnormalities were recognized. Lower numbers of normal colonies and grossly abnormal erythroid colonies [24] were found to be typical of MDS, and the growth of leukemic clusters in culture soon became an acknowledged sign of treatment resistance in AML [25] and of impending leukemic transformation in MDS [26, 27], particularly in patients with autocrine growth factor-independent leukemic proliferation [28, 29]. However, as hematopoietic precursor cell cultures proved difficult to standardize [30] they were gradually replaced by other techniques, and only limited data are available on the impact of the colony-forming assay in the contemporary management of MDS [31].

Prognostic Significance of Progenitor Cell Cultures in MDS
In a retrospective study we therefore examined the value of quantitative and qualitative abnormalities in growth properties of CFU-C derived from $\mathrm{BM}$ and $\mathrm{PB}$ of untreated MDS patients and compared it to established prognostic factors.

\section{Patients and Methods}

Patients and Study Design

This single-center retrospective study included 73 consecutive patients receiving a first diagnosis of MDS between July 1992 and June 2002. The patients fulfilled all three of the following criteria:

(1) Diagnosis of MDS according to WHO criteria.

(2) Complete workup at first diagnosis including PB counts, BM aspirate and trephine biopsy, CFU-C cultures from BM and $\mathrm{PB}$, and cytogenetic analysis as part of the routine panel of tests performed in a patient with suspected MDS at our institution.

(3) Availability of follow-up data on disease course after initial diagnosis.

$\mathrm{BM}$ and $\mathrm{PB}$ from 40 healthy BM donors were used for control CFU-C cultures after informed consent had been obtained.

As diagnostic criteria for MDS changed from FAB to WHO classification during the period in which patients were diagnosed, all records were reevaluated and patients classified according to the WHO classification. Patients no longer classified as having MDS according to WHO [i.e. those with a FAB diagnosis of chronic myelomonocytic leukemia and refractory anemia with excess blasts-1 in transformation (RAEB-t)] were excluded from the study.

The median age of the patients at diagnosis was 66 years (range $13-88) ; 43$ (58.9\%) of the patients were male. The median observation period was 2.8 years (range $0.1-12$ years). At last follow-up 56 patients $(77 \%)$ had died and 17 patients (23\%) were alive. Diagnoses according to the WHO were refractory anemia with or without ringed sideroblasts in 4 patients (5.5\%), refractory cytopenia with multilineage dysplasia with or without ringed sideroblasts in 24 patients (32.9\%), RAEB-1 in 24 patients $(32.9 \%)$, RAEB-2 in 19 patients (26\%), and MDS unclassified in 2 patients (2.7\%). Cytogenetics were 'good risk' (i.e. normal karyotype or isolated $\operatorname{del}(5 q), \operatorname{del}(20 q)$ or $-\mathrm{Y}$ ) in 46 patients (63\%), 'bad risk' (i.e. chromosome 7 abnormalities or complex karyotype) in 15 patients (20.5\%), and 'intermediate risk' in the remaining 12 patients (16.4\%). Risk status according to the IPSS was 'low' in 12 patients (16.4\%), 'intermediate-1' in 34 patients (46.6\%), 'intermediate-2' in 20 patients (20.7\%), and 'high' in 7 patients (9.6\%).

Treatment Modalities

The treatment approach was consistent throughout the observation period. Whenever possible, patients were treated according to a formal protocol: patients at low risk of transformation and those not able to undergo more intensive therapy received supportive care (transfusions, treatment of infections, hematopoietic growth factors); immunosuppressive therapy with antithymocyte globulin/cyclosporine was offered as part of an ongoing trial to patients with a suspected autoimmune cytopenia component; pa- 
tients with elevated blast count and/or impending transformation were treated with AML-like chemotherapy. Younger patients with progressive disease were offered allogeneic hematopoietic stem cell transplantation if a matched sibling or unrelated donor was available.

\section{BM Morphology and Histology}

BM biopsy and aspiration were performed at the posterior superior iliac crest. Biopsy material was fixed in formalin, embedded and stained with hematoxylin/eosin for assessment of morphology and with silver for visualization of fibers. Aspirated material was stained with Wright/Giemsa and iron stain. BM morphology was assessed for cellularity, dysplastic changes, percentage of blast cells, and the presence of ring sideroblasts and fibrosis.

\section{Cytogenetic Analysis}

Cell culture and chromosome preparation were performed on $\mathrm{BM}$ or $\mathrm{PB}$ samples as reported previously $[32,33]$. Chromosomes were stained in $\mathrm{G}$ bands. Karyotypes were described according to the International System for Human Cytogenetic Nomenclature [34].

\section{CFU Cultures}

Culture Media

$600,000 \mathrm{~PB}$ and 100,000 BM cells/ml of culture, respectively, were obtained from heparinized $\mathrm{PB}$ and marrow by Ficoll centrifugation. The untreated adherent cell-containing suspension was washed and cultured in duplicates in commercial methylcellulose medium supplied by StemCell Technologies, Vancouver, B.C., Canada (MethoCult ${ }^{\mathrm{TM}} \mathrm{GH}$ H4431) containing 30\% fetal bovine serum, $1 \%$ bovine serum albumin, $10^{-4} \mathrm{M}$ mercaptoethanol, $2 \mathrm{mM}$ L-glutamine, $50 \mathrm{ng} / \mathrm{ml} \mathrm{SCF}, 10 \mathrm{ng} / \mathrm{ml} \mathrm{GM}$-CSF, $10 \mathrm{ng} / \mathrm{ml}$ IL-3, 3 U erythropoietin/ $/ \mathrm{ml}$ and 70\% Iscove's modified Dulbecco's medium for 14 days in a fully humidified atmosphere at $37^{\circ} \mathrm{C}$ supplemented with $5 \% \mathrm{CO}_{2}$.

\section{Quantification and Morphology of Cultures}

After incubation, colonies were counted in an inverted microscope. The number of CFU-granulocyte, CFU-eosinophil, CFUmacrophage, burst-forming unit-erythroid (BFU-E), and mixed colonies was counted and added to give a total number of colonies. For quantitative analysis, the total number of normal CFU-C was compared to normal ranges derived from a population of healthy donors, independent of colony size, hemoglobinization of BFU-E, E:M ratio and the presence or absence of leukemic clusters. In agreement with standard laboratory practice, we defined the 2.5 th and 97.5 th percentiles of healthy donors' CFU-C counts as lower and upper limits of the normal range. Accordingly, patients with CFU-C counts below the 2.5th percentile (i.e. $<8 \mathrm{CFU}$ C/600,000 PB cells or $<20$ CFU-C/100,000 BM cells) were considered to have a quantitative growth defect. Culture technique and evaluation of healthy donor BM and $\mathrm{PB}$ cultures are subject to international standardization and quality control with yearly ring experiments performed at our institution.

As higher than normal CFU-C counts (i.e. $>112 \mathrm{CFU}-\mathrm{C}$ in $\mathrm{PB}$ or $>235 \mathrm{CFU}-\mathrm{C}$ in $\mathrm{BM}$ ) are almost exclusively seen in patients also displaying leukemic growth, this abnormality was not assessed separately.

Leukemic cluster growth in cultures is characterized by cell agglomerations of visibly abnormal individual nonhemoglo- binized cells of varying size, resembling either granulocytes or macrophages (verified by May-Grünwald-Giemsa staining of individual clusters in case of doubt). In addition to morphological abnormalities, leukemic clusters can be differentiated from colonies by their smaller cell number (typically $<40$ per cluster compared to $>50$ per colony). Counting of leukemic clusters does not give an appropriate estimate of the proliferative potential of leukemic precursors because the dispersion of leukemic growth varies individually. We therefore judged leukemic growth as an allor-none phenomenon. A minimum of 20 leukemic clusters in cultures also containing normal colonies and 10 clusters in otherwise empty cultures were used as cut points. In cases of doubt, individual clusters or colonies were selected and stained to reveal either leukemic or normal myeloid morphology.

For qualitative analysis, the presence of leukemic cluster growth (fig. 1c-f) in either BM or PB culture was considered abnormal. For quantitative analysis, reduced growth in both $\mathrm{PB}$ and marrow was considered abnormal.

\section{Statistical Analysis}

The cohorts stratified by the CFU-C growth pattern were compared using Pearson's $\chi^{2}$ test for discontinuous and MannWhitney test for continuous variables. Rates of overall survival and transformation to AML were estimated using the KaplanMeier method and compared by log rank test. Cox proportional hazards models were used to estimate the impact of individual prognostic factors on multivariate analysis. Patients receiving allogeneic hematopoietic stem cell transplantation were censored for follow-up on the day of the transplant.

\section{Results}

\section{Quantitative CFU Abnormalities in MDS Patients}

Comparison of CFU-C numbers in $\mathrm{PB}$ and marrow of healthy controls and MDS patients showed lower median CFU-C, and a wider range of values in both $\mathrm{PB}$ and marrow in patients than in controls (table 1; fig. 2). Reduction of CFU-C was more pronounced for BFU-E than for myeloid CFU-C, resulting in a reduction of the erythroid: myeloid ratio. Twenty-six of 73 patients (36\%) showed CFU-C numbers in both PB and marrow within the normal range of healthy donors' values and were therefore classified as quantitatively normal, even if they had leukemic cluster growth in addition to morphologically normal colonies. In 10 patients the growth of colonies was completely absent. The differences between colony numbers in normal and MDS patients were more marked for $\mathrm{BM}$ than for $\mathrm{PB}$ cultures, indicating that cultures from $\mathrm{BM}$ have a higher diagnostic power in MDS and cannot be replaced by cultures from PB. Several patients had normal colony growth in PB cultures. Compared with patients displaying normal numbers of CFU-C, patients with quantitative growth defects were more frequently found to have a reduced marrow cellularity, whereas all 

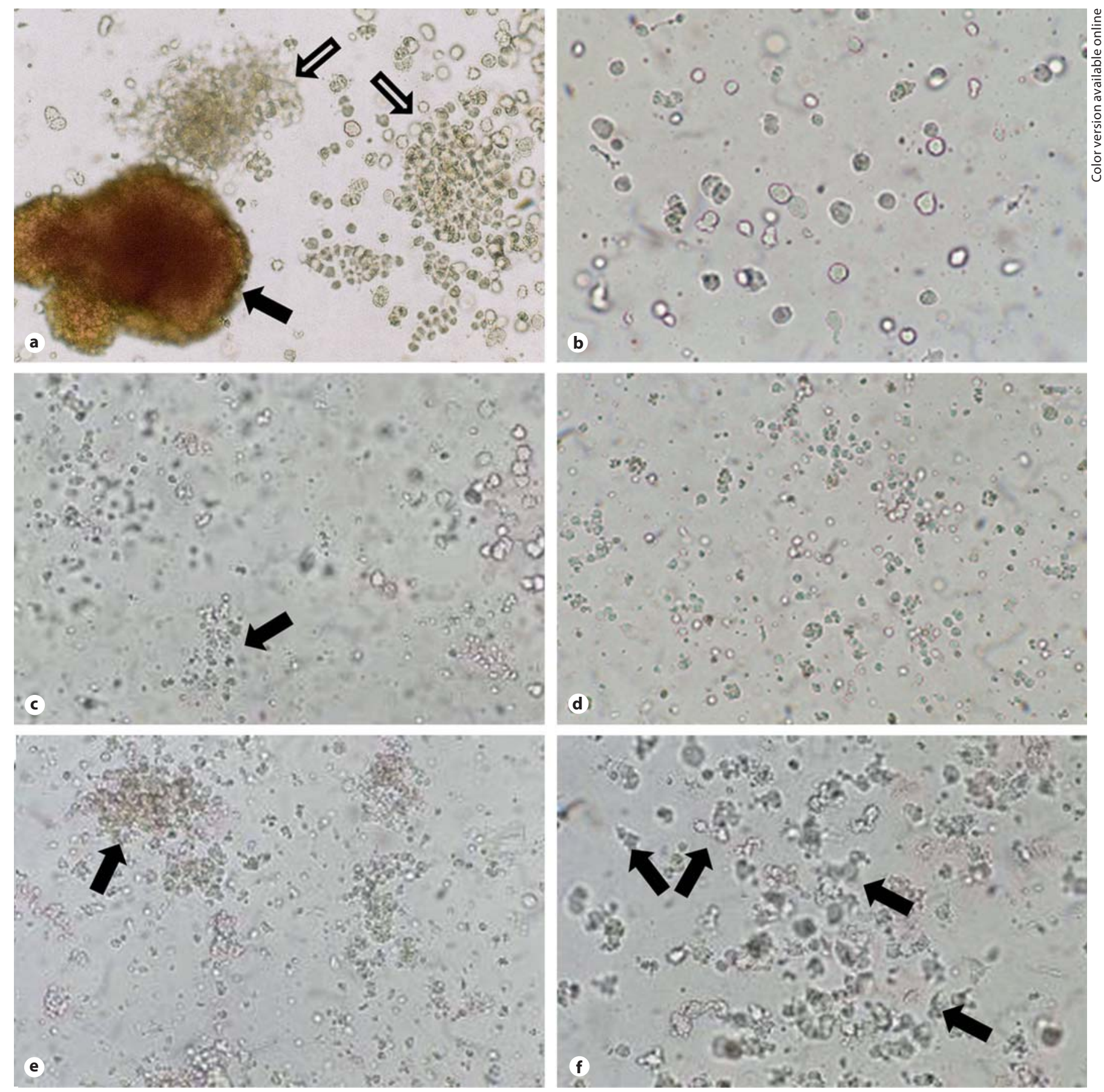

Fig. 1. Representative examples of normal colonies and leukemic cluster growth in patients with MDS (all with $100 \times$ magnification). Normal size and relationship between erythroid (solid arrow) and myeloid colonies (open arrows) in a healthy control donor (a) versus strong reduction of normal erythroid and myeloid colonies in MDS patients (b-f): single dispersed macrophages without leukemic growth (b), small leukemic clusters (c), growth of single isolated leukemic cells (d), large leukemic clusters (e), and leukemic clusters with dendritic cell morphology (f). 
Table 1. CFU-C assays in healthy donors and MDS patients

\begin{tabular}{|c|c|c|c|c|c|}
\hline & \multicolumn{2}{|c|}{ Healthy controls } & \multicolumn{2}{|l|}{ Patients } & \multirow[t]{2}{*}{$\mathrm{p}$} \\
\hline & median & range & median & range & \\
\hline \multicolumn{6}{|c|}{ Peripheral blood } \\
\hline CFU-G & 7 & $0-30$ & 4 & $0-202$ & 0.23 \\
\hline CFU-M/GM & 1 & $0-6$ & 0 & $0-129$ & 0.21 \\
\hline CFU-Eo & 0 & $0-9$ & 0 & $0-13$ & 0.39 \\
\hline BFU-E & 36 & $4-93$ & 4 & $0-336$ & $<0.001$ \\
\hline CFU-GEMM & 0 & $0-7$ & 0 & $0-8$ & 0.006 \\
\hline Total & 46 & $6-115$ & 15 & $0-388$ & $<0.001$ \\
\hline E:M ratio & 3.6 & $1.0-14$ & 0.62 & $0-97$ & $<0.001$ \\
\hline \multicolumn{6}{|l|}{ Bone marrow } \\
\hline CFU-G & 25 & $7-72$ & 6 & $0-192$ & $<0.001$ \\
\hline CFU-M/GM & 27 & $1-120$ & 2 & $0-192$ & $<0.001$ \\
\hline CFU-Eo & 1 & $0-19$ & 0 & $0-8$ & $<0.001$ \\
\hline BFU-E & 35 & $8-96$ & 2 & $0-130$ & $<0.001$ \\
\hline CFU-GEMM & 0 & $0-8$ & 0 & $0-2$ & 0.002 \\
\hline Total & 86 & $20-246$ & 17 & $3-330$ & $<0.001$ \\
\hline E:M ratio & 0.64 & $0.13-2.30$ & 0.17 & $0-6.3$ & 0.01 \\
\hline
\end{tabular}

CFU-G = Neutrophil colonies; CFU-M/GM = granulocyte/ macrophage colonies; CFU-Eo = eosinophil colonies; BFU-E = day 14 erythroid colonies; CFU-GEMM = mixed (erythroid/myeloid) colonies; E:M ratio = erythroid/myeloid ratio.

other prognostic factors were distributed equally (table 2). Despite quantitative abnormalities in MDS patients, no significant differences in disease characteristics were seen between patients with strongly reduced and those with completely absent colony growth. An example of quantitatively and qualitatively normal colony growth is shown in figure 1a. Figure $1 \mathrm{~b}$ shows a culture with a quantitative defect (no colonies), growth of free macrophages and without leukemic growth.

\section{Qualitative CFU Abnormalities}

Of the known qualitative growth abnormalities including small colony size and inadequate hemoglobinization of BFU-E, only leukemic alteration of CFU-GM was analyzed. Figure 1c-f show examples of leukemic growth, as observed in more than half of the patients $(39 / 73,53 \%)$. Compared to patients without leukemic growth, patients with leukemic CFU-C growth were significantly younger (60 vs. 71 years), had more frequently elevated blast counts and bad-risk cytogenetics, and were accordingly more frequently diagnosed with high-risk MDS according to WHO (RAEB-I and II) and IPSS (see table 2).

A significant proportion of patients showed both qualitative and quantitative abnormalities: of 39 patients with

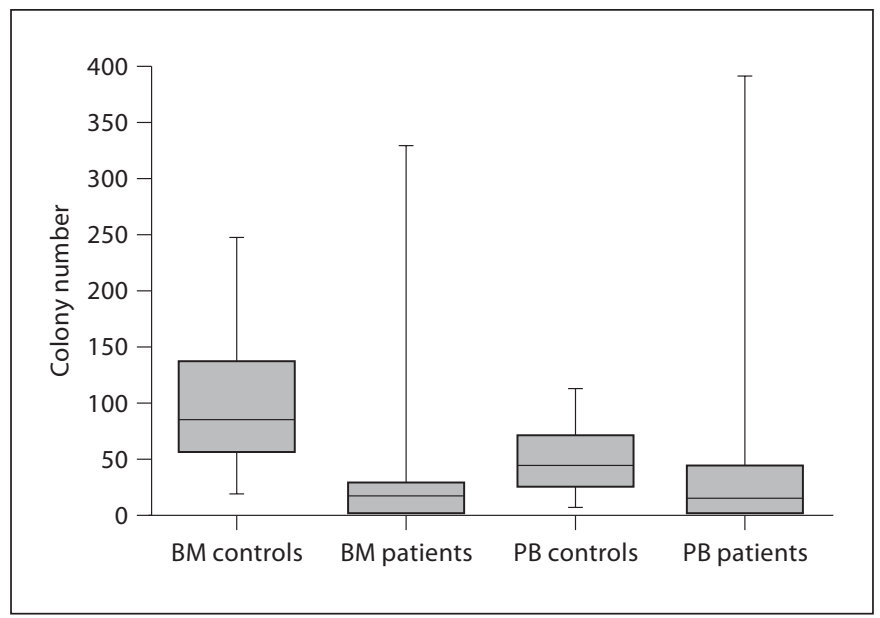

Fig. 2. Total colony numbers per $100,000 \mathrm{BM}$ and $600,000 \mathrm{~PB}$ cells, respectively, in 2-week cultures from healthy controls and MDS patients. Boxes represent median (horizontal line), 25th and 75th percentile (edge of boxes), and whiskers represent minimal and maximal values.

leukemic growth, $12(31 \%)$ at the same time showed reduced/absent colony growth compared to $41 \%$ of patients without leukemic growth $(\mathrm{p}=0.35)$. Only 2 patients had completely normal colony growth, including numbers, colony size, hemoglobinization of BFU-E, $\mathrm{PB}: \mathrm{BM}$ and $\mathrm{E}$ : $\mathrm{M}$ ratio and absence of leukemic clusters.

\section{Impact of CFU-C Abnormalities on Overall Survival in Univariate Analysis}

Quantitative abnormalities of CFU-C had no measurable effect on the disease course: both median survival (1.70 \pm 0.26 vs. $1.91 \pm 0.42$ years) and frequency of longterm survivors $(20 \pm 8$ vs. $17 \pm 6 \%)$ were similar in patients with reduced and those with normal CFU-C numbers (fig. 3e). Equally, within the subgroup of patient with leukemic CFU-C growth, quantitative abnormalities had no impact with a median survival of $1.50 \pm 0.41$ years for patients with leukemic clusters and reduced growth versus $1.45 \pm 0.40$ years for patients with leukemic clusters and quantitatively normal colony growth $(\mathrm{p}=0.71)$.

On the other hand the presence of leukemic cell growth significantly predicted a worse disease course: patients with leukemic cells had a median survival of 1.45 years $( \pm 0.31)$ compared to 2.88 years $( \pm 1.75)$ in patients without leukemic growth (fig. 3a, $\mathrm{p}=0.0004$ ). Estimated 10 -year overall survival was $34 \%( \pm 8)$ in patients without compared to only $4 \%( \pm 4)$ in patients with leukemic CFU-C growth. Four patients with leukemic growth were alive at 
Table 2. Patient characteristics

\begin{tabular}{|c|c|c|c|c|c|c|}
\hline & \multicolumn{3}{|c|}{ Leukemic growth } & \multicolumn{3}{|c|}{ Quantitative growth } \\
\hline & $\begin{array}{l}\text { no } \\
(\mathrm{n}=34)\end{array}$ & $\begin{array}{l}\text { yes } \\
(n=39)\end{array}$ & $\mathrm{p}$ & $\begin{array}{l}\text { reduced } \\
(\mathrm{n}=34)\end{array}$ & $\begin{array}{l}\text { normal/increased } \\
(\mathrm{n}=39)\end{array}$ & $\mathrm{p}$ \\
\hline Age at diagnosis ${ }^{1}$, years & $71(23-87)$ & $60(13-88)$ & 0.03 & $65(33-88)$ & $66(17-88)$ & 0.32 \\
\hline \multicolumn{7}{|l|}{ Gender } \\
\hline Male & $22(64.7)$ & $21(53.8)$ & \multirow[t]{2}{*}{0.35} & $16(61.5)$ & $27(57.4)$ & \multirow[t]{2}{*}{0.74} \\
\hline Female & $12(35.3)$ & $18(46.2)$ & & $10(38.5)$ & $20(42.6)$ & \\
\hline \multicolumn{7}{|l|}{ Etiology } \\
\hline Primary & $28(82.4)$ & $34(87.2)$ & \multirow[t]{2}{*}{0.83} & $22(84.6)$ & $40(85.1)$ & \multirow[t]{2}{*}{0.84} \\
\hline Therapy related & $6(17.6)$ & $5(12.8)$ & & $4(15.4)$ & $7(14.9)$ & \\
\hline \multicolumn{7}{|l|}{ WHO diagnosis } \\
\hline RA/RARS & $4(11.8)$ & $1(2.6)$ & \multirow[t]{5}{*}{0.03} & $1(3.8)$ & $4(8.5)$ & \multirow[t]{5}{*}{0.10} \\
\hline RCMD/RCMD-RS & $15(44.4)$ & $9(23.1)$ & & $9(34.6)$ & $15(31.9)$ & \\
\hline RAEB-1 & $7(20.6)$ & $16(41.0)$ & & $5(19.2)$ & $18(38.3)$ & \\
\hline RAEB-2 & $6(17.6)$ & $13(33.3)$ & & $11(42.3)$ & $8(17.0)$ & \\
\hline MDS-U & $2(5.9)$ & $0(0.0)$ & & $0(0.0)$ & $2(4.3)$ & \\
\hline \multicolumn{7}{|l|}{ Cytogenetics } \\
\hline Good risk & $27(79.4)$ & $20(51.3)$ & \multirow[t]{3}{*}{0.03} & $18(69.2)$ & $29(61.7)$ & \multirow[t]{3}{*}{0.71} \\
\hline Intermediate risk & $4(11.8)$ & $7(17.9)$ & & $4(15.4)$ & $7(14.9)$ & \\
\hline Bad risk & $3(8.8)$ & $12(30.8)$ & & $4(15.4)$ & $11(23.4)$ & \\
\hline \multicolumn{7}{|l|}{ Marrow cellularity } \\
\hline Hypoplastic & $5(14.7)$ & $4(10.3)$ & \multirow[t]{2}{*}{0.41} & $6(23.1)$ & $3(6.4)$ & \multirow[t]{2}{*}{0.04} \\
\hline Normo/hypercellular & $29(85.3)$ & $35(89.7)$ & & $20(76.9)$ & $44(93.6)$ & \\
\hline \multicolumn{7}{|l|}{ Marrow fibrosis } \\
\hline No & $29(85.3)$ & $13(33.3)$ & \multirow{2}{*}{0.07} & $20(76.9)$ & $12(25.5)$ & \multirow[t]{2}{*}{0.82} \\
\hline Yes & $5(14.7)$ & $26(66.7)$ & & $6(23.1)$ & $35(74.5)$ & \\
\hline Serum $\mathrm{LDH}^{1}$ & $191(128-385)$ & $208(100-1,224)$ & 0.42 & $189(121-699)$ & $203(100-1,224)$ & 0.40 \\
\hline \multicolumn{7}{|l|}{ PB cytopenia } \\
\hline $0-1$ lineages & $18(52.9)$ & $15(38.5)$ & \multirow[t]{2}{*}{0.22} & $12(46.2)$ & $21(44.7)$ & \multirow[t]{2}{*}{0.90} \\
\hline 2-3 lineages & $16(47.1)$ & $24(61.5)$ & & $14(53.8)$ & $26(55.3)$ & \\
\hline \multicolumn{7}{|l|}{ IPSS score } \\
\hline Low risk & $11(32.4)$ & $2(5.1)$ & \multirow[t]{4}{*}{0.001} & $4(15.4)$ & $9(19.1)$ & \multirow[t]{4}{*}{0.65} \\
\hline Intermediate-1 & $16(47.1)$ & $17(43.6)$ & & $11(42.3)$ & $22(46.8)$ & \\
\hline Intermediate-2 & $6(17.6)$ & $14(35.9)$ & & $7(26.9)$ & $13(27.7)$ & \\
\hline High risk & $1(2.9)$ & $6(15.4)$ & & $4(15.4)$ & $3(6.4)$ & \\
\hline
\end{tabular}

Unless otherwise indicated figures represent number with the percentage in parentheses. RA = Refractory anemia; RARS $=$ refractory anemia with ringed sideroblasts; RCMD = refractory cytopenia with multilineage dysplasia; RCMD-RS = refractory cytopenia with multilineage dysplasia and ringed sideroblasts; RAEB = refractory anemia with excess blasts; MDS-U = MDS unclassified.

${ }^{1}$ Values represent median with the range in parentheses.

last follow-up: 3 of these had received allogeneic stem cell transplantation early in the course of the disease.

Importantly, if analysis was restricted to patients with an intermediate-risk IPSS score - the largest group of MDS patients and at the same time the subgroup in which therapeutic decisions are notoriously difficult - leukemic CFU-C growth retained its prognostic impact (fig. 3c). In IPSS low-risk patients, who in this cohort represent a total of 13 patients, leukemic growth at diagnosis was seen in 2 patients. Both patients transformed to AML early during follow-up ( 1 after 9 months, the other after 35 months), while only one transformation to AML was seen in the other 11 IPSS low-risk patients without leukemic growth at initial diagnosis.

\section{Impact of CFU-C Abnormalities on Transformation to} $A M L$ in Univariate Analysis

Analysis of transformation to AML showed that leukemic CFU-C growth at diagnosis was a strong predictor for early transformation to AML: transformation rate 


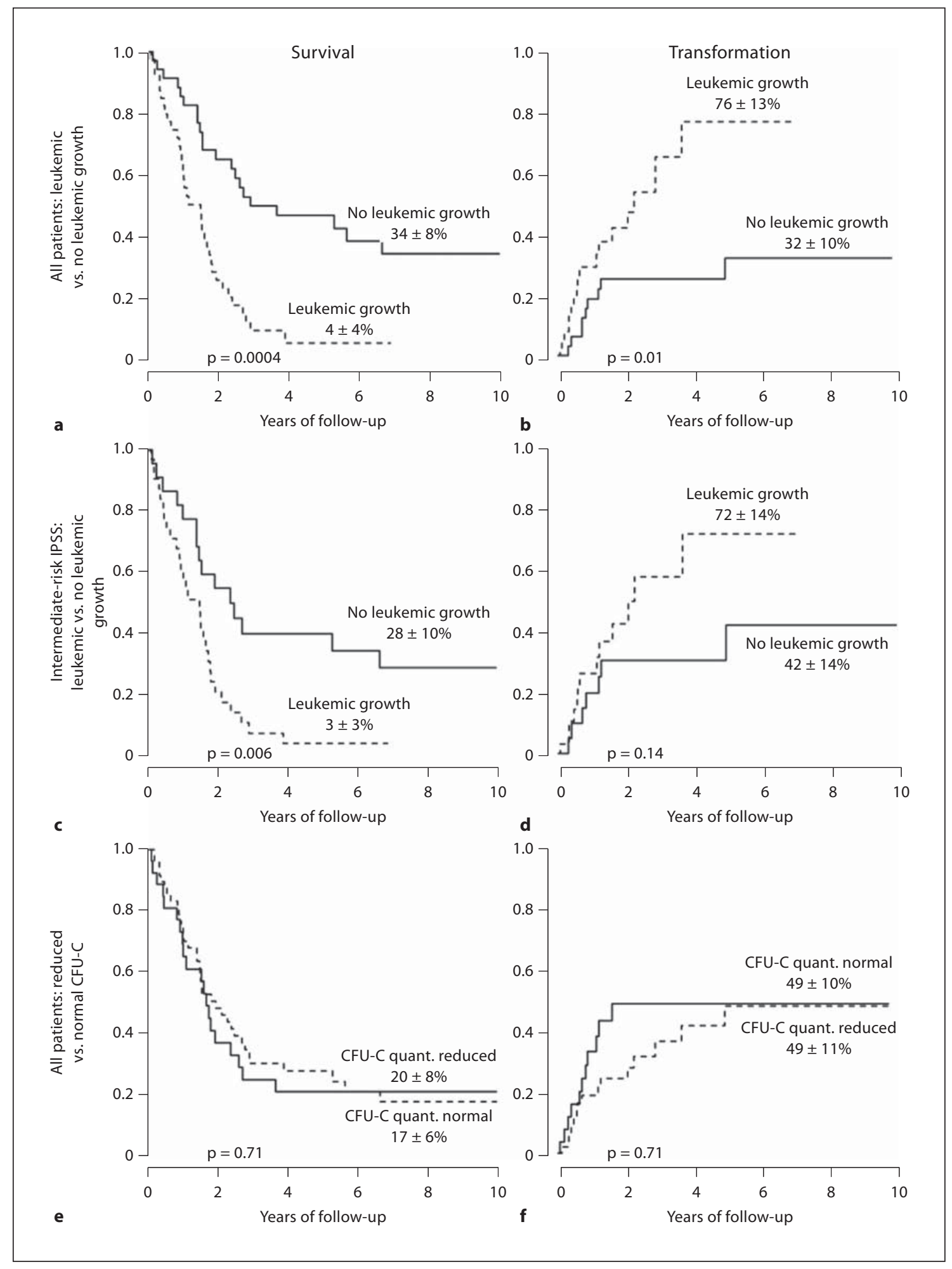

Fig. 3. Survival and transformation to AML in patients with MDS stratified by CFU-C growth at diagnosis: leukemic growth versus no leukemic growth in all patients $(\mathbf{a}, \mathbf{b})$ and in patients with intermediate-risk IPSS (c, d). e, $\mathbf{f}$ Survival and transformation rate in patients stratified according to reduced versus normal colony number. quant. = Quantitatively. 
Table 3. Multivariate analysis

\begin{tabular}{|c|c|c|c|c|c|c|}
\hline \multirow[t]{2}{*}{ Risk factor } & \multicolumn{3}{|c|}{ Survival } & \multicolumn{3}{|c|}{ Transformation } \\
\hline & $\mathrm{RR}$ & $95 \% \mathrm{CI}$ & $\mathrm{p}$ & $\mathrm{RR}$ & $95 \% \mathrm{CI}$ & $\mathrm{p}$ \\
\hline \multicolumn{7}{|l|}{ CFU-C } \\
\hline No leukemic clusters & 1.00 & - & - & 1.00 & - & - \\
\hline Leukemic clusters & 2.12 & $1.08-4.16$ & 0.03 & 2.63 & $1.06-6.53$ & 0.04 \\
\hline Normal/increased growth & 1.00 & - & - & 1.00 & - & - \\
\hline Reduced growth & 0.77 & $0.38-1.56$ & 0.47 & 0.80 & $0.30-2.13$ & 0.66 \\
\hline \multicolumn{7}{|l|}{ Cytogenetics } \\
\hline Good risk & 1.00 & - & - & 1.00 & - & - \\
\hline Intermediate risk & 1.89 & $0.83-4.28$ & 0.12 & 3.18 & $1.12-9.04$ & 0.03 \\
\hline Bad risk & 2.21 & $1.04-4.69$ & 0.04 & 3.62 & $1.27-10.4$ & 0.02 \\
\hline \multicolumn{7}{|l|}{ Blast count } \\
\hline$<5 \%$ & 1.00 & - & - & 1.00 & - & - \\
\hline $6-10 \%$ & 1.81 & $0.84-3.94$ & 0.13 & 0.91 & $0.30-2.74$ & 0.85 \\
\hline $11-19 \%$ & 2.17 & $0.96-4.90$ & 0.06 & 1.97 & $0.67-5.83$ & 0.22 \\
\hline \multicolumn{7}{|l|}{ Age at diagnosis } \\
\hline$\leq 60$ years & 1.00 & - & - & 1.00 & - & - \\
\hline$>60$ years & 1.97 & $1.04-3.74$ & 0.04 & 1.22 & $0.53-2.78$ & 0.65 \\
\hline \multicolumn{7}{|l|}{ Ringed sideroblasts } \\
\hline Not present & 1.00 & - & - & 1.00 & - & - \\
\hline Present & 0.63 & $0.28-1.43$ & 0.27 & 0.16 & $0.03-0.77$ & 0.02 \\
\hline
\end{tabular}

was $76 \pm 13 \%$ for patients with leukemic growth compared to only $32 \pm 10 \%$ in patients without initial leukemic growth (fig. $3 b, p=0.01$ ). Again, leukemic growth retained its prognostic impact in patients with an intermediate-risk IPSS (fig. 3d). Patients with reduced CFU-C growth on the other hand showed transformation rates comparable to those with quantitatively normal CFU-C assays ( $49 \pm 11$ vs. $49 \pm 10 \%, p=0.71$, fig. $3 f)$.

\section{Leukemic Growth Is an Independent Poor \\ Prognostic Factor}

Multivariate analysis confirmed the results of univariate analysis. Leukemic growth emerged as an independent predictor of survival [relative risk (RR) 2.12, 95\% confidence interval 1.08-4.16] and transformation to AML (RR 2.63, 95\% CI 1.06-6.53, table 3). The only other significant prognostic factor for both survival and transformation was cytogenetics. High marrow blast count and older age negatively influenced survival, and the presence of ringed sideroblasts was strongly protective against transformation while having only a statistically nonsignificant effect on survival. The quantity of CFU-C had no impact on survival and risk of transformation in multivariate analysis along with all other variables tested (marrow hypoplasia, marrow fibrosis, number of PB cytopenias, serum LDH, gender and etiology).

\section{Discussion}

In this retrospective study including 73 patients with newly diagnosed MDS, quantitative and qualitative abnormalities of hematopoietic precursor cell colony growth were frequent: more than half of patients showed leukemic cluster growth, whereas 1 out of 3 patients had strongly reduced or absent colony growth. While leukemic cluster growth was associated with other high-risk factors such as bad-risk cytogenetics and high marrow blast count, reduced colony growth was found more frequently in patients with hypoplastic marrow but was not associated with any other commonly assessed risk factor. Only 2 patients had completely normal colony growth at diagnosis. Both were alive at 8 and 10 years of follow-up, respectively, without having received cytoreductive treatment.

While having the limitation of being retrospective, this study with a long observation period allowed us to study the impact of abnormalities in quantitative and qualitative growth at first diagnosis on survival and risk of transformation. Leukemic cluster growth at diagnosis emerged as a highly sensitive predictor of transformation to AML and early death, whereas quantitative reduction of colony growth had no significant impact on the disease course. Multivariate analyses confirmed the significant 
value of leukemic cluster growth as a prognostic factor independent of other variables such as high marrow blast count and bad-risk cytogenetics. A limitation of our study is that patients referred to a tertiary center might not be entirely representative of the general population of patients with MDS, as younger patients and those with high-risk features may be more likely to be referred to a university hospital.

Our results are in line with numerous early $[26,28]$ and some more recent [31,35-37] studies on the prognostic value of clonogenic assays in patients with MDS. The classification of MDS has undergone fundamental changes in recent years: RAEB-t and chronic myelomonocytic leukemia, two former FAB entities where leukemic growth was typically found, are no longer classified as MDS. Our results underline that leukemic growth has an independent prognostic impact in patients classified according to WHO and IPSS. These two classifications are widely used today to stratify patients into different risk groups and are useful to the clinician in defining an optimal treatment strategy, which can go from observation to early allogeneic stem cell transplantation. The fact that colony-forming cell assays identify a subpopulation at high risk of transformation and early death indicates that it may be of particular use in this situation. Our study further suggests that for young patients with leukemic growth at diagnosis, allogeneic transplantation should be considered early in the disease course, even if they are considered low or intermediate risk by IPSS: of 33 patients with leukemic growth, only 4 were alive at last follow-up, 3 of whom had received allogeneic stem cell transplantation early in the disease course.

Our study also demonstrates that diagnostic cultures using standard conditions and commercially available reagents have a high prognostic value. A recent comparative study in our laboratory showed that, using nonseparated cell suspensions containing factor-producing accessory cells in standardized medium, leukemic growth is not factor dependent. While using growth factor-free medium and separation of progenitor and accessory cells have the advantage of elucidating pathological mechanisms such as auto-/paracrine growth factor production involved in leukemic cluster growth, we chose simple culture conditions because of routine clinical feasibility.

Drawbacks of diagnostic cultures and reasons why they were widely abandoned were the technical difficulties in preparing the media, lack of standardization, and the inevitable individual variability of different observers. However, up to now the culture technique has been simplified and internationally standardized mainly for the quantitative assay of functionally normal stem cells for stem cell transplantation. The same media can be used for detection of qualitative growth abnormalities.

In conclusion, we propose that precursor cell cultures deserve reappraisal as a valuable additional tool in the clinical management of MDS. CFU-C cultures add a functional dimension to the standard morphological and cytogenetic criteria currently used to classify patients according to WHO and IPSS. Most importantly, CFU-C cultures make it possible to identify a subgroup of patients at very high risk of disease progression and transformation to AML. Leukemic growth as a reliable early sign of transformation to AML stresses the urgent need for aggressive therapy in patients eligible for it.

\section{Acknowledgments}

We thank all collaborators of the Unité de cytogénétique du cancer for performing chromosome analysis and providing cytogenetic data, in particular Valérie Parlier, Dominique Mühlematter, Valérie Beyer and Alexander Genitsch for data management.

M.B. is supported by research grants from the Swiss National Science Foundation and the European Hematology Association. M.S. is supported by research grants from the Swiss Cancer League and the Swiss National Science Foundation.

\section{References}

1 Larson RA: Myelodysplasia: when to treat and how. Best Pract Res Clin Haematol 2006; 19:293-300.

-2 Steensma DP, Bennett JM: The myelodysplastic syndromes: diagnosis and treatment. Mayo Clin Proc 2006;81:104-130.

- 3 Martino R, Iacobelli S, Brand R, Jansen T, van Biezen A, Finke J, Bacigalupo A, Beelen D, Reiffers J, Devergie A, Alessandrino E, Mufti GJ, Barge R, Sierra J, Ruutu T, Boo- gaerts M, Falda M, Jouet JP, Niederwieser D, de Witte T: Retrospective comparison of reduced-intensity conditioning and conventional high-dose conditioning for allogeneic hematopoietic stem cell transplantation using HLA-identical sibling donors in myelodysplastic syndromes. Blood 2006;108:836846.

4 Meletis J, Viniou N, Terpos E: Novel agents for the management of myelodysplastic syn- dromes. Med Sci Monit 2006;12:RA194RA206.

5 Harris NL, Jaffe ES, Diebold J, Flandrin G, Muller-Hermelink HK, Vardiman J, Lister TA, Bloomfield CD: World Health Organization classification of neoplastic diseases of the hematopoietic and lymphoid tissues: report of the Clinical Advisory Committee meeting - Airlie House, Virginia, November 1997. J Clin Oncol 1999;17:3835-3849. 
6 Greenberg P, Cox C, LeBeau MM, Fenaux P, Morel P, Sanz G, Sanz M, Vallespi T, Hamblin T, Oscier D, Ohyashiki K, Toyama K, Aul C, Mufti G, Bennett J: International scoring system for evaluating prognosis in myelodysplastic syndromes. Blood 1997;89:20792088.

-7 Germing U, Gattermann N, Strupp C, Aivado M, Aul C: Validation of the WHO proposals for a new classification of primary myelodysplastic syndromes: a retrospective analysis of 1,600 patients. Leuk Res 2000;24: 983-992.

8 Germing U, Strupp C, Kuendgen A, Isa S, Knipp S, Hildebrandt B, Giagounidis A, Aul C, Gattermann N, Haas R: Prospective validation of the WHO proposals for the classification of myelodysplastic syndromes. Haematologica 2006;91:1596-1604.

9 Cermak J, Michalova K, Brezinova J, Zemanova Z: A prognostic impact of separation of refractory cytopenia with multilineage dysplasia and 5q- syndrome from refractory anemia in primary myelodysplastic syndrome. Leuk Res 2003;27:221-229.

10 Nimer SD: Clinical management of myelodysplastic syndromes with interstitial deletion of chromosome 5q. J Clin Oncol 2006; 24:2576-2582.

11 Komrokji RS, Bennett JM: The clinical implications of the World Health Organization's classification of myelodysplastic syndromes. Curr Hematol Rep 2005;4:175-181.

$\checkmark 12$ Bernasconi P, Klersy C, Boni M, Cavigliano PM, Calatroni S, Giardini I, Rocca B, Zappatore R, Caresana M, Quarna J, Lazzarino $\mathrm{M}$, Bernasconi $\mathrm{C}$ : Incidence and prognostic significance of karyotype abnormalities in de novo primary myelodysplastic syndromes: a study on 331 patients from a single institution. Leukemia 2005; 19:1424-1431.

-13 Sole F, Luno E, Sanzo C, Espinet B, Sanz GF, Cervera J, Calasanz MJ, Cigudosa JC, Milla F, Ribera JM, Bureo E, Marquez ML, Arranz E, Florensa L: Identification of novel cytogenetic markers with prognostic significance in a series of 968 patients with primary myelodysplastic syndromes. Haematologica 2005;90:1168-1178.

14 Cutler CS, Lee SJ, Greenberg P, Deeg HJ, Perez WS, Anasetti C, Bolwell BJ, Cairo MS, Gale RP, Klein JP, Lazarus HM, Liesveld JL, McCarthy PL, Milone GA, Rizzo JD, Schultz KR, Trigg ME, Keating A, Weisdorf DJ, Antin JH, Horowitz MM: A decision analysis of allogeneic bone marrow transplantation for the myelodysplastic syndromes: delayed transplantation for low-risk myelodysplasia is associated with improved outcome. Blood 2004; 104:579-585.
15 Komrokji RS, Bennett JM: Evolving classifications of the myelodysplastic syndromes. Curr Opin Hematol 2007; 14:98-105.

16 Marisavljevic D, Cemerikic V, Rolovic Z, Boskovic D, Colovic M: Hypocellular myelodysplastic syndromes: clinical and biological significance. Med Oncol 2005;22:169-175.

17 Lambertenghi-Deliliers G, Orazi A, Luksch R, Annaloro C, Soligo D: Myelodysplastic syndrome with increased marrow fibrosis: a distinct clinico-pathological entity. Br J Haematol 1991;78:161-166.

18 Maschek H, Georgii A, Kaloutsi V, Werner M, Bandecar K, Kressel MG, Choritz H, Freund M, Hufnagl D: Myelofibrosis in primary myelodysplastic syndromes: a retrospective study of 352 patients. Eur J Haematol 1992;48:208-214.

19 Germing U, Hildebrandt B, Pfeilstocker M, Nosslinger T, Valent P, Fonatsch C, Lubbert M, Haase D, Steidl C, Krieger O, Stauder R, Giagounidis AA, Strupp C, Kundgen A, Mueller T, Haas R, Gattermann N, Aul C: Refinement of the international prognostic scoring system (IPSS) by including LDH as an additional prognostic variable to improve risk assessment in patients with primary myelodysplastic syndromes (MDS). Leukemia 2005;19:2223-2231.

20 Mano H: DNA micro-array analysis of myelodysplastic syndrome. Leuk Lymphoma 2006;47:9-14.

21 Ueda M, Ota J, Yamashita Y, Choi YL, Ohki R, Wada T, Koinuma K, Kano Y, Ozawa K, Mano H: DNA microarray analysis of stage progression mechanism in myelodysplastic syndrome. Br J Haematol 2003;123:288296.

22 Marisavljevic D, Rolovic Z, Boskovic D, Colovic M: Long-term survivors in myelodysplastic syndromes: clinical and biological characteristics. Med Oncol 2004;21:333338.

23 Breccia M, Mancini M, Nanni M, D’Elia GM, Carmosino I, Latagliata R, Sarlo C, Mandelli F, Alimena G: Clinical features of prognostic significance in myelodysplastic patients with normal karyotype at high risk of transformation. Leuk Res 2005;29:33-39.

24 Chui DH, Clarke BJ: Abnormal erythroid progenitor cells in human preleukemia. Blood 1982;60:362-367.

25 Iscove NN, Senn JS, Till JE, McCulloch EA: Colony formation by normal and leukemic human marrow cells in culture: effect of conditioned medium from human leukocytes. Blood 1971;37:1-5.

26 Verma DS, Spitzer G, Dicke KA, McCredie $\mathrm{KB}$ : In vitro agar culture patterns in preleukemia and their clinical significance. Leuk Res 1979;3:41-49.
27 Jacobs A: Myelodysplastic syndromes: pathogenesis, functional abnormalities, and clinical implications. J Clin Pathol 1985;38: 1201-1217.

28 Francis GE, Wing MA, Miller EJ, Berney JJ, Wonke B, Hoffbrand AV: Use of bone-marrow culture in prediction of acute leukaemic transformation in preleukaemia. Lancet 1983;i:1409-1412.

29 Lowenberg B, van Putten WL, Touw IP, Delwel R, Santini V: Autonomous proliferation of leukemic cells in vitro as a determinant of prognosis in adult acute myeloid leukemia. N Engl J Med 1993;328:614-619.

30 Richert-Boe KE, Bagby GC Jr: In vitro hematopoiesis in myelodysplasia: liquid and softgel culture studies. Hematol Oncol Clin North Am 1992;6:543-556.

31 Marisavljevic D, Rolovic Z, Sefer D, Basara N, Ilic D, Boskovic D, Colovic M: Biological and clinical significance of clonogenic assays in patients with myelodysplastic syndromes. Med Oncol 2002;19:249-259.

32 Castagne C, Muhlematter D, van Melle G, Gachoud V, Jotterand Bellomo M: Effect of conditioned media, nutritive elements, and mitotic synchronization on the accuracy of the cytogenetic analysis in acute nonlymphocytic leukemia patients presenting with inv(16)/t $(16 ; 16)$ or $t(15 ; 17)$. Cancer Genet Cytogenet 1997;94:106-112.

33 Jotterand Bellomo M, Parlier V, Muhlematter D, Grob JP, Beris P: Three new cases of chromosome 3 rearrangement in bands q21 and q26 with abnormal thrombopoiesis bring further evidence to the existence of a 3 q21q26 syndrome. Cancer Genet Cytogenet 1992;59:138-160.

34 Mitelman F: An International System for Human Cytogenetic Nomenclature. Basel, Karger, 1995.

35 Raymakers R, Preijers F, Boezeman J, Rutten E, De Witte T: Prognostic implications of bone marrow culturing in myelodysplastic syndrome: a retrospective analysis. Leuk Lymphoma 1994;14:111-120.

>36 Berer A, Jager E, Sagaster V, Streubel B, Wimazal F, Sperr WR, Welterman A, Schwarzinger I, Frommlet F, Haas OA, Valent P, Lechner K, Geissler K, Ohler L: Circulating myeloid colony-forming cells predict survival in myelodysplastic syndromes. Ann Hematol 2003;82:271-277.

-37 Raymakers R, De Witte T, Joziasse J, Van der Lely N, Boezeman J, Haanen C: In vitro growth pattern and differentiation predict for progression of myelodysplastic syndromes to acute nonlymphocytic leukaemia. Br J Haematol 1991;78:35-41. 